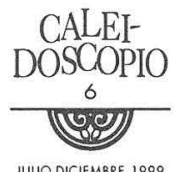

\title{
El territorio de Jalisco
}

JOSÉ MARÍA MURIÁ

El Colegio de Jalisco

La historia, con minúscula, entendida como la suma de lo que ha transcurrido y el objeto de estudio del historiador, es única e indivisible y está compuesta por un número infinito de acontecimientos, hechos, situaciones, fenómenos o como se les quiera llamar -todos relacionados en mayor o menor medida entre sí-, de los cuales solamente unos cuantos dejan vestigios. Con base en esos testimonios o vestigios se pretende saber qué ocurrió y, lo más importante, su razón de ser -el porqué de su existencia-, a efecto de coadyuvar a entender mejor lo que sucede en la actualidad.

Algunos teóricos de este menester, quizá demasiado optimistas, presumen que la buena comprensión del pasado permite intuir el futuro y, en cierta medida, tener una previsión de él. Lo que sí está claro es que de cualquier división que se haga de la historia, aún de conformidad con sus coordenadas fundamentales -el espacio y el tiempo-, deberá tenerse plena conciencia de que se trata de una sección o de una división meramente artificial. El fraccionamiento es indispensable, si se quiere ver desde un punto de vista metodológico, ante la imposibilidad evidente de aprehender cabalmente toda la historia; sin embargo, tales fracciones nunca deben considerarse inherentes a la historia misma. Más bien resultan un requerimiento historiográfico determinado por las necesidades y las posibilidades del autor y su particular circunstancia. 
Recordemos aquello de que el Hombre -con mayúscula- es en esencia él mismo y su circunstancia, como se le achaca a Ortega y Gasset, pero ahora que somos un tanto más deterministas quizás invertiríamos los factores en aras de modificar el producto y diríamos que el Hombre es su circunstancia y él mismo.

Así pues, podría afirmarse que, en sentido estricto, no hay épocas o regiones per se diferentes, sino perspectivas muy variables de acuerdo con las circunstancias, a partir de las cuales se trazan líneas imaginarias en el tiempo y en el espacio que forman épocas y regiones y las separan unas de otras. Todo ello se hace según ciertas características que conviene o interesa destacar y que, por lo mismo, se elevan al grado de esenciales. En un caso se pretende reconocer y tipificar los cambios insoslayables; en otro, de lo que se trata es de establecer las diferencias cuya existencia no es tan evidente.

Cabe aquí evocar el ejemplo del río que, a pesar de tener sus aguas características distintas en las orillas y en el centro del cauce, o según se esté más cerca de su desembocadura o de sus fuentes, resulta imposible establecer una precisa delimitación de ellas.

Sin embargo, en la medida en que los habitantes aumentan y se reducen los espacios despoblados, se requiere una mayor precisión al formular esas divisiones del territorio que responden a exigencias administrativas. Recuérdese que las hemos llamado "políticas", pues responden a la necesidad dē "vivir en policía", como se decía en los siglos XVI y XVII, o también al imperio de la polis, desde donde se ejerce y ministra el poder.

Si hubiera regiones absolutas o delimitables en la concordancia con todos los puntos de vista posibles, pudiéramos entonces hablar de divisiones políticas inmanentes, cuya existencia sobrevendría al margen y de manera independiente de la acción cambiante del ser humano y de la mutabilidad de las sociedades. Pero no es así; las divisiones políticas o administrativas resultan de la manera como se va relacionando una sociedad -en esencia cambiante- con un 
paisaje relativamente estable. Así que suponer que tales límites son perpetuos es tan absurdo como prescindir de ellos para ayudarnos a penetrar en el conocimiento de la historia. Precisamente su relación con el devenir social y con el espacio geográfico mismo, hacen que el estudio de la historia de los límites permita adentrarnos en la sociedad que produce el cambio y, al mismo tiempo, ayuda a entender y definir los trazos-actuales.

En consecuencia, cualquier modificación que se haga hoy de la colindancia entre jurisdicciones deberá tomar en cuenta las necesidades contemporáneas, pero también los antecedentes que una buena historia pueda aportar. La historia de los límites, igual que cualquier otra expresión historiográfica, no habrá de entenderse como una forma de disputa, de cuya esterilidad o, peor aún, nocividad, dieron ya suficientes muestras los historiadores polémicos de antaño y hogaño en favor de liberales o de conservadores, sino como un medio para saber bien a bien lo que se tiene entre manos y poder asumir decisiones más convenientes.

En el caso del occidente de México, por obra y gracia de su particular poblamiento, de su compleja topografía y de su accidentada historia, se ha producido una marcación mucho más complicada que en otras partes del país. Sinuosas líneas van y vienen en los mapas siguiendo hipotéticamente crestas, ríos y cejas de mesetas, aunque en el terreno real su precisión deje mucho que desear.

En este caso son mínimos los antecedentes prehispánicos, manifiestos sólo en algunas poblaciones importantes de ese tiempo que sobrevivieron como cabeceras jurisdiccionales, como serían los casos, entre otros, de Etzatlán, Ahuacatlán, Tlajomulco, Tonalá y Centispac. Pero no debe perderse de vista que básicamente es una historia que comienza con la conquista española y la creación del vastísimo reino de Nueva Galicia, cuyo territorio abarcaría a los estados de Nayarit, Zacatecas y Aguascalientes, una buena parte de Jalisco y un pedacito intermedio de Sinaloa. Por su parte, Michoacán, Guanajuato, San Luis Potosí, Colima y lo que hoy se conoce 
como el sur de Jalisco, intervienen en este rejuego con la representación del vecino reino de la Nueva España, mientras que Durango y el sur de Sinaloa lo hacen con la camiseta de Nueva Vizcaya.

Éste es, pues, el pie de cría:

1. Las tierras primeramente colonizadas por gente de Hernán Cortés, en pos de metales preciosos y un puerto que facilitara nuevas expediciones en dirección poniente, acabaron siendo novohispanas.

2. Neogallegas serían en primera instancia las tierras colonizadas por cuenta de Nuño de Guzmán desde 1530, con intenciones fallidas de obtener fáciles riquezas y formar un gran todo junto con la Provincia del Pánuco; en segunda instancia, lo que se agenciaron las expediciones que fueron desde Compostela hacia el noreste, en pos de minerales, a partir de 1546 y que llegaron hasta Concepción del Oro.

3. En tercer lugar las neovizcaínas, resultado de la colonización que, a partir de 1561, promovió desde la ciudad de México el virrey Luis de Velasco, alentado por los yacimientos argentíferos de Zacatecas y las evidencias de que había muchos más en dirección hacia el norte. ${ }^{2}$

Si Nueva Galicia, por obra y gracia del establecimiento de la villa de la Purificación en 1532, dispuesto ${ }^{3}$ por Guzmán, le ganó a Hernán Cortés tierras en el sur y la actual costa de Jalisco, en las que éste no había logrado que se asentaran colonizadores ni evan-

1 Recuérdese que Nuño de Guzmán era gobernador de la Provincia del Pánuco al momento de emprender la conquista del occidente de México. No fue hasta fines de 1531 cuando se enteró de que había dejado de serlo.

2 Conviene estar alerta para no confundir, como ha sucedido antaño y hogaño, el obispado de Guadalajara, la jurisdicción de la Audiencia y la gobernación de Nueva Galicia, fueron tres entidades que coincidieron en un gran superficie, pero también difirieron de manera sustantiva.

3 Fue Juan Fernández de Híjar quien se encargó de la fundación, cerca de donde está actualmente. 
gelizadores, ${ }^{4}$ lo mismo haría Francisco de Ibarra cuando recolonizó tierras de la actual Sinaloa en favor de Nueva Vizcaya. Pero en este caso el resultado fue más complejo, puesto que -como dice Mota Padilla- "cercenó Ibarra... no sólo la tierra que había de Sinaloa a Culiacán [al norte de esta población], sino aún la tierra que mediaba entre Culiacán y Compostela". ${ }^{5}$ En este paraje intermedio fue donde Nuño de Guzmán había fundado en 1531 la efímera villa de Chiametla, que Ibarra estableció de nueva cuenta con mayor éxito.

Otra trifulca territorial entre las nuevas Vizcaya y Galicia fue la jurisdicción de Nombre de Dios, cuyo ayuntamiento se había organizado desde Guadalajara en 1563 y al año siguiente había sido transformado por Ibarra. La consecuente disputa se aplacó en 1579 cuando el virrey Martín Enríquez de Almanza dispuso que ni con melón ni con sandía y le nombró personalmente un alcalde mayor que dependería de México hasta 1786, cuando Nombre de Dios se sumo a la naciente intendencia de Durango. ${ }^{6}$

Una tercera muesca a Nueva Galicia se produjo al crearse, alrededor de 1589, el peculiar Gobierno de las Fronteras de San Luis de Colotlán, a efecto de proteger del acoso de los indios "bárbaros" a los españoles de Jerez y Tlaltenango que abastecían de maíz a los minerales zacatecanos y a los indios sedentarios que habían sido ya sometidos. Para su gobierno el virrey nombraría un "capitánprotector", con facultades amplísimas. ${ }^{7}$

4 Para las consecuentes disputas entre ambos conquistadores, ver Pleito del Marqués del Valle contra Nuño de Guzmán, sobre aprovechamiento de Pueblos de la Provincia de Avalos. Introd. y notas de Salvador Reynoso. Guadalajara, Font, 1961 (Documentación Histórica Mexicana, 1).

5 Matías de la Mota Padilla. Historia del Reino de Nueva Galicia en la América Septentrional. Guadalajara, Instituto Nacional de Antropología e Historia-Universidad de Guadalajara, 1973, cap. XLI, p. 208, (Obras Facsimilares, 3).

6 Peter Gerhard. Geografía histórica de la Nueva España. 1519-1821. México, UNAM, 1986, p. 210.

7 Robert D. Shadow. "Conquista y gobierno español" en Relaciones. Zamora, El Colegio de Michoacán. Vol. viI, núm. 32, otoño, 1987, p. 42 y ss. 


\section{(ए2)}

Cada una de estas grandes unidades territoriales formarían alcaldías mayores o corregimientos, con sede en un centro de población de relativa importancia y potestad sobre una superficie diferente que "partía términos" con la cabecera vecina. Su número cambiaría mucho al principio de la Colonia, pero andando el tiempo se llegó a una cantidad más o menos estable. ${ }^{8}$ Asimismo, las dimensiones de cada una de estas entidades sería muy diferente. Dos de ellas, Aguascalientes y Colima, dieron lugar a un estado de la República y cinco formaban lo que ahora es Nayarit, pero hubo otras mucho más pequeñas.

Con el nombre de partido o departamento, tales entidades sobrevivieron a todos los cambios habidos hasta la segunda década del siglo XX, cuando fueron clausuradas de un plumazo -en el caso particular del estado de Jalisco el 2 de julio de 1914- ${ }^{9}$ para darle vida al municipio moderno, tan oficialmente "libre" como a merced en la realidad de las decisiones de los gobiernos estatales y federales. ${ }^{10}$

La conquista en 1722 de la región conocida como San José de Nayarit y también como Nuevo Toledo, aunque acabó como una dependencia neogallega, fue el primero de muchos cambios que se produjeron durante el siglo XVIII. Entre éstos vale recordar dos: en

8 Según Domingo Lázaro de Arregui había 31 en 1621, y de acuerdo con Matías de la Mota Padilla llegaban a 33 en 1742.

9 Decreto núm. 3 de Manuel M. Diéguez, dado en el palacio provisional de Ahualulco, Jalisco.

10 Las municipalidades se generalizaron con base en las disposiciones constitucionales de 1824 de que hubiera un gobierno en cada población con más de mil habitantes y, por lo menos, una persona que supiera leer y escribir para que pudiera fungir como secretario. Sin embargo, no asumió desde el principio la condición de una extensión territorial determinada. 
1734 se solventó la articulación de la provincia de Culiacán, cuando se creó la de San Felipe y Santiago de Sinaloa, con tierras también de Nueva Vizcaya, pero separadas de Durango por la Sierra Madre y en 1767, una buena porción de Charcas pasó a la Nueva España y acabó perteneciendo a San Luis Potosí.

Finalmente, Carlos IV expidió el 6 de diciembre de 1786 en Madrid la famosa Real Ordenanza para el establecimiento e instrucción de intendentes de ejército y provincia en el reino de la Nueva Espa$\tilde{n} a$, que transformó de pies a cabeza toda la administración colonial, con ánimo de establecer con mayor claridad las atribuciones de los funcionarios.

En relación con Nueva Galicia, dicha Ordenanza dio lugar a dos intendencias, la de Guadalajara y la de Zacatecas, cuya separación era evidente, a pesar de que la primera había sido desde 1560 la capital del reino, pues las atribuciones fiscales dadas a Zacatecas para que el producto de sus minas marchara directamente a México sin injerencia alguna de Guadalajara y otras prebendas ganadas con la energía de su riqueza, le fueron dando una independencia real a dicha ciudad y a su área de influencia, por cierto de una geografía asaz diferente, que la fue apartando del resto de Nueva Galicia. Desde tiempos antiguos se hablaba comúnmente de Zacatecas y de Guadalajara o Xalisco como dos provincias diferentes, correspondientes a la división que establecieron los franciscanos desde principios del siglo XVII.

Otra intendencia, además de la de Durango, fue la de Arizpe "con la jurisdicción ó territorio de las dos Provincias de Sonora y Sinaloa", ${ }^{11}$ conocidas oficialmente desde 1776 como Provincias Internas.

11 Real ordenanza para el establecimiento e instrucción de intendentes de ejército y provincia en el reino de la Nueva España. 1786. Introd. de Ricardo Rees Jones. México, UNAM, 1984, última página. 
A partir de entonces, las alcaldías mayores se llamarían generalmente "partidos", mas algunos de ellos cambiarían de adscripción, pues las nuevas divisiones políticas concebidas en España no resultaron del todo satisfactorias. Aparte de que el actual sur de Jalisco pertenecería desde el principio del cambio a la intendencia de Guadalajara, en 1795 se le sumó también el partido de Colima que había quedado originalmente en Valladolid. Al mismo tiempo, empezó a procurarse que Aguascalientes y Juchipila pasasen a Zacatecas, lo que se concretó en octubre de 1803.

Por su parte, la peculiar jurisdicción de Colotlán sobreviviría hasta fines de la Colonia, ${ }^{12}$ aunque de su seno había surgido en 1754 el corregimiento de Bolaños, a resultas del auge de sus minerales. Bolaños se incorporó con todas las de la ley a la intendencia de Guadalajara en 1791.

Así quedaron configuradas las dos grandes entidades -Jalisco y Zacatecas- que, después de la Constitución de Cádiz, se convertirían en provincias ${ }^{13}$ y el entusiasmo federalista de 1823 haría de ellas estados libres y soberanos. No obstante, cuando imperó el criterio republicano centralista, dichos estados se transformaron en departamentos y sus atribuciones fueron sumamente restringidas. Finalmente, llegamos a la condición actual en que la legislación les garantiza el nombre de estados y el epíteto de "libres y soberanos", pero que la reglamentación reduce en la realidad a verdaderos departamentos.

Además, con ánimo de podar un tanto su energía, el gobierno central favoreció regionalismos particulares, prohijando el nacimiento de entidades de menor tamaño. Tal fue el caso de la separa-

12 Robert D. Shadow (op. cit., p. 63) cree que sobrevivió hasta 1821, aunque es posible que se haya disuelto un poco antes.

13 La provincia de Guadalajara, incluyendo a Zacatecas, se estableció al implantarse por primera vez la dicha Constitución en 1814, aunque de sus siete diputados, tres serían zacatecanos. Pero al restablecerse la Constitución en 1820, pronto emergió por sí sola la provincia de Zacatecas. 
ción del partido de Colima en el mismo año de 1823, aprovechando que su integración a Jalisco era muy reciente y no faltaba en ese lugar a quien le interesara un mayor aislamiento, como deseaban los adinerados entronizados en su ayuntamiento. Mientras Nicolás Bravo y Pedro Celestino Negrete se apersonaban al frente de sus respectivas tropas en Lagos, atrayendo la atención y las huestes del gobernador Luis Quintanar, el coronel Anastasio Brizuela -según instrucciones recibidas de México- ${ }^{14}$ preparó la escisión declarando que el "N. Ayuntamiento, autoridades y vecinos" lo habían obligado a aceptar la separación, amén de que consideró que así lo exigían "la justicia y la razón". ${ }^{15}$ De inmediato se hizo también el intento de agregarle el partido de Zapotlán el Grande, pero su guarnición militar no se prestó al juego y permaneció fiel al gobierno de Jalisco.

Colima se convirtió oficialmente en territorio de la federación el 30 de enero de 1824 y en 1836, ante las exigencias jaliscienses de que le fuese reintegrado, se decidió anexarlo al estado de Michoacán. No fue hasta 1846 cuando recobró su calidad de territorio, y en 1857 se transformó también en estado de la federación.

Por otro lado, el partido de Aguascalientes aprovechó en 1835 el pertinaz federalismo zacatecano para atender los reclamos de la oligarquía local. Según la leyenda, un beso de bella dama convenció a Santa Anna de escindirlo de Zacatecas y convertirlo en territorio de la federación. Finalmente, aunque volvió transitoriamente a Zacatecas, la Constitución de 1857 hizo también de Aguascalientes un estado libre y soberano de la República.

Más consistente se antoja el proceso separatista de Nayarit, aunque resultó mucho más largo y penoso, a pesar de que también con-

14. Dichas instrucciones fueron interceptadas en Guadalajara, pero, según se estilaba, las que fueron enviadas por otra vía sí llegaron a su destino.

15 Luis Pérez Verdía. Historia particular del estado de Jalisco, desde los primeros tiempos de que hay noticia hasta nuestros días. 2a. ed. Guadalajara, Gobierno del Estado de Jalisco, 1952, t. II, p. 268. 
tó con la buena disposición del gobierno de México, especialmente de Manuel González y Porfirio Díaz. Conviene recordar que el mismo Ramón Corona, quien conocía a fondo la problemática de esta región, opinaba que para arreglar lo que se llamaba "la cuestión de Tepic" se requería o de un ejército fabuloso y de mucho tiempo y dinero, o de instalar la capital de Jalisco en el cantón de Tepic.

- En este caso lo que formaría un nuevo territorio federal, declarado así oficialmente por el congreso el 30 de octubre de 1884, no sería un partido -o departamento, según la nomenclatura federalsino todo un cantón. ${ }^{16}$ Era el cantón más rico de Jalisco, excepción hecha del de Guadalajara. Estaba formado por cinco departamentos y antiguas alcaldías mayores: Compostela, Ahuacatlán, Tepic, Centispac y Acaponeta, y había ganado cierta cohesión en torno a la población que fungía también como cabecera cantonal: Tepic -oficialmente ciudad desde 1814-. El puntal de la región había sido el puerto de San Blas, de penosa poblanza a causa de la insalubridad ambiental, lo que favoreció el crecimiento y la hegemonía de Tepic.

Muestra de lo difícil que había resultado la separación de Tepic, transformado en estado de Nayarit en 1917, fue el primer periódico publicado en esta región en 1846, El Vigía del Pacífico, que tenía como intención primigenia abogar por la separación cantonal del resto de Jalisco.

En realidad fue el gobierno liberal de Benito Juárez el que obró en consecuencia ante la imperiosa necesidad de que el cantón de Tepic se independizara. En 1867, en plena euforia republicana por el triunfo contra la intervención francesa y el imperio, y al tiempo que los militares jaliscienses se aprestaban a arremeter en contra de Manuel Lozada; Juárez, haciendo poco caso de las leyes y con

16 Los cantones, que agrupaban varios departamentos o partidos, fueron establecidos solamente en Jalisco y Veracruz y desaparecieron también en 1914. En Jalisco hubo ocho en 1824, pero acabó teniendo doce. 
el deseo de proteger a "El Tigre", creó el distrito militar de Tepic, cuyo jefe político dependería directamente del presidente de la República. La verdad es que aquí acabó la injerencia de Jalisco, pues, no obstante las repetidas protestas, el tránsito de distrito militar a territorio de la federación fue directo.

Esta narración podría enriquecerse, entre muchas cosas más, con los intentos fallidos de separar el cantón de Lagos y anexarlo al estado de Aguascalientes desde que se restauró la República; la pretensión de algunos pobladores del cantón de Autlán de pasarse a Colima, dolidos por la creación, a sus costillas, del cantón de Mascota en 1870; el contubernio de Manuel Lozada con el jerarca de este último cantón, Remigio Tovar. para sumarse al distrito militar de Tepic en aquel mismo tiempo, etcétera.

Asimismo, podria hablarse de la efímera división general del país en 50 departamentos que preparó Manuel Orozco y Berrả y promulgó Maximiliano el 3 de marzo de 1865. Todo ello constituye una verdadera historia de lo que pudo haber sido y no fue, pero que también tenía su razón de ser. Comoquiera, las cosas quedaron como están y ahora sólo resta resolver confusiones y discrepancias limítrofes entre estados, que apasionan a varios, entusiasman a otros y a algunos también nos divierten. 


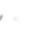

